\title{
Studies on the effects of mixed light-thermal ageing on parchment by vibrational spectroscopy and micro hot table method
}

\author{
Federica Cappa ${ }^{1{ }^{*}}\left(\mathbb{D}\right.$, Ilaria Paganoni ${ }^{1,2 \dagger}$, Cristina Carsote $^{3 \dagger}$, Elena Badea ${ }^{4,5 \dagger}$ and Manfred Schreiner ${ }^{1 \dagger}$
}

\begin{abstract}
The damaging effects of mixed light-thermal ageing on parchment were studied by exposing mock-ups to artificial light $\left(162 \mathrm{~W} / \mathrm{m}^{2}\right.$ irradiance) at controlled temperature and relative humidity $\left(52^{\circ} \mathrm{C}, 30 \% \mathrm{RH}\right)$ for up to $748 \mathrm{~h}$, with testing being made during this time incrementally. The physical-chemical changes (deterioration) resulting from these conditions were analysed by applying FTIR-ATR and Raman spectroscopy, colorimetric measurements and MHT. The deterioration found includes the formation of collagen-destabilised intermediate states which then progressively convert to disorganised structures, e.g. pregelatinised collagen and gelatin. The process is characterized by molecular changes of collagen associated with its photo-oxidation. These are shown by changes in the position and intensity of the main FTIR absorption bands of collagen, namely those of Amide I, Amide II, and Amide III, as well as by the occurrence and the increase of a shoulder at $1740 \mathrm{~cm}^{-1}$. The shrinking activity of the collagen fibres in the parchment mock-ups was measured by the micro-hot-table $(\mathrm{MHT})$ method, which revealed the presence of multiple collagen populations with distinct thermal stabilities and confirmed the deterioration pattern suggested by the molecular changes.
\end{abstract}

Keywords: Parchment, Mixed light-thermal ageing, Deterioration, Vibrational spectroscopy, MHT method

\section{Introduction}

Parchment is one of the most important media that was used historically for recording written information. During the medieval period, manuscripts were made almost exclusively from parchment. According to Herodotus' Terpsichore (484-425 BC) and Pliny's Natural History (79 AD), the use of parchment was a common practice since the patronage of Eumenes of Pergamum, the city where parchment processing seems to have been developed [1] and from where the material's name derives. Parchment is obtained from raw animal hides through a sequence of steps during which they are thoroughly washed, soaked

\footnotetext{
*Correspondence: f.cappa@akbild.ac.at

${ }^{\dagger}$ Federica Cappa, Ilaria Paganoni, Cristina Carsote, Elena Badea and

Manfred Schreiner contribute equally to this work

${ }^{1}$ Institute of Natural Sciences and Technology in the Arts, Academy

of Fine Arts Vienna, Schillerplatz 3, 1010 Vienna, Austria

Full list of author information is available at the end of the article
}

in a solution containing lime, dehaired, scraped with sharp knives (to remove muscle tissue and hypodermic layers), finished (by mechanical thinning, shaving, bleaching, dying, polishing) and finally tightened on rectangular or circular frames on which they are left to dry under tension at ambient temperature [2]. The manufacturing procedure of parchment differs depending on the geographical area and the historical period, but the term "parchment" is generally associated with the "Western" (European) preparation method that uses calcium hydroxide extensively that has been carried out since the Middle Ages. Compared to the previously used papyrus, a material intrinsically brittle and sensitive to moisture, parchment is characterized by longer durability, stability, and very good optical properties [2,3]. Its opacity allowed writing on both grain and corium sides, and its robustness led to the recycling of old classical manuscripts, a practice that became very common during the Middle Ages due to the great demand for parchment [4]. 
From the chemical point of view, collagen is the main structural component of the skin, and hence of parchment. The structure of collagen gives parchment its strength and durability over time, even though the repair mechanisms which functioned in collagen in vivo (turnover) are obviously no longer active in a post-mortem tissue. Parchment deterioration generally occurs as a result of improper environmental and storage conditions or inappropriate conservation and/or restoration treatments. The process of manufacture may also alter the structure of collagen in a manner that initiates its deterioration $[5,6]$. The most important physical and chemical parameters which can induce collagen deterioration are temperature, humidity, light irradiation, chemical pollutants, solvents, as well as their synergistic actions. Their effects were ascribed to three main deterioration paths: molecular denaturation, hydrolysis, and oxidation [3, $5,6]$. It is also necessary to consider that collagen deterioration generally occurs at different levels, i.e. from the macroscopic to the molecular levels, and alterations to the hierarchical structure arise as a result of molecular damage. When the collagen molecules break down, the structural hierarchy is lost, inducing irreversible damage and the weakening of the material.

Both static and dynamic accelerated ageing experiments have been performed to study these processes occurring in this material in significantly less time than under natural conditions; these consisted of modifying external parameters such as temperature, light, relative humidity and the presence of pollutants [7-17]. A dry heat treatment at $100{ }^{\circ} \mathrm{C}$ was applied by Della Gatta et al. [7] and Badea et al. [8] in order to explicitly examine heat-induced effects such as thermal destabilisation, and to quantify the distribution of collagen structures during ageing. Similar levels of deterioration and comparable damage patterns as those induced by heat were found for some historical samples that have undergone heat flattening and/or heat drying treatments [8]. By dry heating in the range of $60-170{ }^{\circ} \mathrm{C}$ for $48 \mathrm{~h}$, Fessas et al. [9] found a correlation between the denaturation temperature and the water content in parchment (moisture), allowing the quantification of the degree of deterioration degree experienced by parchments. Most recently, Mühlen Axelsson et al. [10] applied a dry heat treatment of $120{ }^{\circ} \mathrm{C}$ to study the heat-induced oxidation of parchment and found significant colour changes, a decrease in hydrothermal stability, as well as changes in the amino acid composition. On the other hand, an X-ray diffraction study of parchment exposed to dry heating at $120^{\circ} \mathrm{C}$ showed that this method is not appropriate to simulate some of the changes in molecular packing occurring during natural ageing [11] although dehydrothermal treatment may mimic some of the properties of historical parchment such as oxidative damage of amino acid side chains. The synergistic effects of dry heating and visible light irradiation are also reported. Such treatments showed an intensification of the dynamics of destabilisation and denaturation of collagen with ageing time [12]. Thermal ageing below $100{ }^{\circ} \mathrm{C}$ with differing relative humidity conditions, in both static and dynamic ageing, was performed by Vest et al. [13] and Badea et al. [14] to understand how much heat and relative humidity are actually necessary to create an accelerated degradation rate. Their results showed that (i) temperature increase induces significant variations of the hydrothermal and structural parameters, whereas the influence of $\mathrm{RH}$ depends on predefined ratios of the ageing conditions; (ii) parchment can fairly easily withstand exposure to $40{ }^{\circ} \mathrm{C}$ when $\mathrm{RH}<60 \%$ but; (iii) for $\mathrm{RH}$ between 60 and $80 \%$, thermal denaturation will increase, which accelerates as temperature increases further. In a more complex ageing experiment that included the ageing effects of chemical pollutants $\left(\mathrm{SO}_{2}, \mathrm{NO}_{\mathrm{x}}\right.$ and combined $\left.\mathrm{SO}_{2}+\mathrm{NO}_{\mathrm{x}}\right)$, Budrugeac et al. [12] and Badea et al. [15] could demonstrate that pollutant attack and damage is significantly enhanced by preheating treatments. Badea et al. [14, 15] were able to establish the dynamics of deterioration by quantifying the change in collagen distribution as a function of thermal stability during the ageing treatment.

Fewer experiments focus on the artificial light-ageing of parchments. Manfredi et al. [16] reported the use of quantitative multispectral imaging for monitoring the degradation of parchment caused by light exposure at $50 \% \mathrm{RH}$ and $30{ }^{\circ} \mathrm{C}$, whereas Dolgin et al. [17] investigated the effect of UV radiation in order to set up a nondestructive optical method for rapid assessment of the stage of parchment deterioration. Light has a high potential for damaging collagen-based materials, the extent of which is dependent on environmental factors, e.g. the temperature and relative humidity. Consequently, investigations of the impact of light were conducted with the aim of understanding its interaction-mechanisms with collagen molecules and correlate them with the condition of collagen-based historical and archaeological objects. This issue is extremely important for the fresh (unaged) collagen-based biomaterials as well.

The main focus of this work was a systematic study of photo-oxidative deterioration of parchment provoked by sunlight irradiation. The photochemistry of pure collagen in aqueous solution, powder and film was already been extensively studied [18-28]. Photo-oxidation due to UV irradiation can cause structural damage of collagen molecules by weakening and cleaving the covalent bonds near the amino acid residues (i.e. proline) in the single chain $[22,23]$. As described in 1994 by Feller [24], the chemical bonds at the $\mathrm{C} \alpha$ atom are split by the free radicals formed 
by the UV irradiation and thus the fragmentation of the molecule is promoted. This process is described as the auto-oxidation of organic materials, and it can be triggered by electromagnetic irradiation (photo-activation) or in some cases also by thermal activation [5, 10, 24]. In proteins, highly reactive radicals generated by radiation (high energy radiation, UV, visible light, thermal) can cause damage at both backbone sites (i.e. $\alpha$-carbon) and reactive side chains [25], while oxidation of the side chains is manifested as a reduction of the number of basic amino acids such as arginine, hydroxylysine, and lysine. The oxidative breaking of the $\mathrm{N}-\mathrm{C}$ covalent bonds that link neighbouring amino acid residues results in the cleavage of the polypeptide chains. It was shown that oxidative cleavage of the collagen molecules occurs preferentially at tyrosyl residues of the collagen molecule [26, 27] or in regions of charged residues [28].

The experiment in this work was carried out to study the damaging effects of mixed light-thermal ageing on collagen in the solid phase, as found in parchment. They simulated as much as possible the photo-oxidation deterioration effect by means of artificial light ageing experiments at controlled temperature and relative humidity. The monitoring and evaluation of the physical-chemical changes induced by accelerated ageing was performed by applying non-invasive infrared spectroscopy in ATR acquisition mode (FTIR-ATR), Raman spectroscopy and colorimetric measurements, together with the MicroHot-Table (MHT) method, a micro-invasive method widely accepted and applied in the field of conservation science. The advantage of this protocol of analysis is that it can easily be transferred to the assessment of historical parchments.

\section{Materials and methods}

\section{Sample preparation}

The experiment was carried out using calf parchment that was handmade at the Advanced Research for Cultural Heritage Laboratory (ARCH Lab) of the National Research \& Development Institute for Textiles and Leather in Bucharest (INCDTP-ICPI) using technology inspired from ancient recipes. Two mock-ups sized $1 \times 3 \mathrm{~cm}^{2}$ identified as PUV1 and PUV2 were taken from a whole parchment sheet and placed in a UVACUBE SOL 2/400F UV chamber (Dr. Hönle, Germany). To ensure uniform exposure of the parchment samples to the irradiation source, PUV1 was placed on the chamber plate with the grain side facing up, whereas PUV2 was placed with the corium side to the light source. The progress of molecular and structural alterations was monitored by analysing the samples before treatment and after 12, 83, 248,392 , and $748 \mathrm{~h}$ of exposure.
The mock-ups were exposed to artificial light irradiation using a Xenon Arc Simulator lamp with emitting radiation between 295 and $3000 \mathrm{~nm}$, similar to the spectrum of solar radiation. The irradiance of the Xenon lamp was measured in both the visible and UV ranges by means of a UV-Meter Basic (Dr. Hönle, Germany). The measured irradiance value was around $162 \mathrm{~W} / \mathrm{m}^{2}$, corresponding to the yearly natural outdoor conditions in Central Europe (ca. $5000 \mathrm{MJ} / \mathrm{m}^{2}$ or $160 \mathrm{~W} / \mathrm{m}^{2}$ per year) [29-31]. Radiant exposure is defined as the time integral of irradiance $\left(\mathrm{W} \times \mathrm{s} / \mathrm{m}^{2}=\mathrm{J} / \mathrm{m}^{2}\right)$ and the use of Xenon Arc lamp has the advantage of a very good correlation with natural sunlight in terms of spectral irradiance $\left(\mathrm{W} \times \mathrm{m}^{-2} \times \mathrm{nm}\right)$ [24]. Therefore, it can be assumed that the ageing performed at $162 \mathrm{~W} / \mathrm{m}^{2}$ is rather similar to the natural ageing caused by solar radiation [2931 . As the temperature and relative humidity can not be customized in the chamber, a sensor AQL S500 (Aeroqual Limited, New Zealand) was used to monitor these parameters. In general, they were constant (i.e. about $52{ }^{\circ} \mathrm{C}$ and $30 \% \mathrm{RH}$ ) throughout the whole experiment. Under these conditions (low relative humidity and temperature) both the mechanism and the kinetics of light-induced deterioration are affected. This is not a drawback of the experiment, but rather an advantage because light never acts as a single factor, and its effect is intensified by high temperatures and low relative humidity as explained earlier $[7,8]$. Recently, Carsote et al. [32] compared the behaviour of collagen in parchment and leather aged at $70{ }^{\circ} \mathrm{C}$ and $30 \% \mathrm{RH}$. They found that the simultaneous exposure to visible light irradiation induced an evident thermal stabilisation for short ageing times (i.e. up to $384 \mathrm{~h}$ ) which then gradually declined.

It is known that the moisture content (water) in parchment changes depending on the external conditions to which it is exposed, and this also causes changes in its physical-chemical properties [33, 34]. For example, the temperature of denaturation of collagen in collagen-based materials is directly related to its moisture content $[9,15]$. We can thus predict that parchment samples exposed at $50{ }^{\circ} \mathrm{C}$ and $30 \% \mathrm{RH}$ will not undergo complete thermal denaturation in a short time, thus enabling a slow-ageing process more similar to the natural one. The concurrent action of high temperature, low relative humidity, and light irradiation can be expected to exacerbate the photo-oxidation process, thus these parameters were selected as an alternative to the more commonly applied thermal ageing.

\section{Applied analytical methods Infrared spectroscopy in attenuated total reflection mode (FTIR-ATR)}

For the FTIR-ATR investigations, a Lumos FTIR-Microscope (Bruker Optics, Germany) was used. This instrument is equipped with a motorized germanium crystal 
with an $8 \times$ magnification objective, an independent LED white light illumination and a high-resolution CCD camera. The ATR germanium crystal uses an internal pressure control with a resulting penetration depth of about $0.65 \mu \mathrm{m}$ and analysed area of $100 \times 100 \mu \mathrm{m}^{2}$.

Spectra were acquired using Opus software (Bruker Optics, Germany) in the range between 4000 and $370 \mathrm{~cm}^{-1}$ by performing 64 scans with a resolution of $4 \mathrm{~cm}^{-1}$. As parchment is intrinsically inhomogeneous, FTIR-ATR single-point mapping was performed by defining a grid of 9 measurement points (3x3) for both grain and corium sides.

\section{Raman spectroscopy}

Raman measurements were performed in dark room using the ProRaman-L-Dual-G of EnwaveOptronics (California, USA) which is a fully integrated and portable Raman spectrometer. As excitation source, a laser diode emitting at $785 \mathrm{~nm}(\sim 350 \mathrm{~mW})$ with a narrow linewidth of $2.0 \mathrm{~cm}^{-1}$ was used. The fiber optic probe has a standard working distance of $7.5 \mathrm{~mm}$ and it is coupled with a Rayleigh filter. The detector is a cooled $\left(-60{ }^{\circ} \mathrm{C}\right) \mathrm{CCD}$ array detector with a spectral range in the Near-Infrared, from $\sim 100$ to $3300 \mathrm{~cm}^{-1}$. The integrated microscope is equipped with a 1.3 Megapixel camera with in-line LED illumination. Six measurement points were visualized by means of a Leica 50x LWD (Long Working Distance) objective (spot size $\sim 3.14 \mu \mathrm{m}$ ) on both corium and grain sides of the parchment samples. For a reproducible selection of the points, a self-made grid was designed, allowing measurements to be made every $4 \mathrm{~mm}$. The data processing was done with Opus 7.0 software (BrukerOptics, Germany) by computing the spectral average between the acquisition points for each sample side. The obtained spectra were evaluated by comparison to a reference database of ISTA (ISTA ${ }^{1}$ database).

\section{Colorimetric studies}

The SPM50 Gretag-Machbeth system (X-Rite Spectro Eye, Switzerland) was employed to acquire the reflection spectra of the samples in the measurement range from 380 to $730 \mathrm{~nm}$. The samples were illuminated with a D65 light source for accurate colour perception and evaluation. Furthermore, a 10 Degree Supplementary Standard Observer, which is thought to be a closer approximation of human colour perception was used, and reflection was measured relative to the white standard of the instrument.

${ }^{1}$ ISTA: Institute of Natural Sciences and Technology in the Arts, Academy of Fine Arts Vienna.
After calibrating the instrument with an internal-blank standard, 3 spots (spot diameter $1 \mathrm{~mm}$ ) were measured on each sample side, for both, unaged and aged samples. The three-dimensional CIEL"a*b* (1994) colour space theory [35] was applied for the evaluation of the data.

\section{Shrinkage activity by micro hot table (MHT) method}

Thermal microscopy or MHT method is a combined technique based on the microscopic analysis of collagen fibres subjected to controlled heating (heating rate: $\left.2{ }^{\circ} \mathrm{C} / \mathrm{min}\right)$ in the temperature range $\left(20-100{ }^{\circ} \mathrm{C}\right)$. Collagen fibres have the intrinsic property of shrinking when heated in an aqueous environment, reducing their length by up to a quarter. The hydrothermal stability and structural heterogeneity of collagen fibres is evaluated based on their shrinkage activity [36-38].

The parchment micro-samples (about 0.05-0.1 mg) were taken from both PUV1 and PUV2 samples aged for $748 \mathrm{~h}$. Since artificially aged parchment generally shows homogeneous thermal behaviour, 2 fresh micro-samples were taken from the exposed surfaces: grain side of PUV1 and corium side of PUV2. The analyses were performed using MHT equipment composed of a Linkam LTS120 micro heating plate (Linkam Scientific Instruments) equipped with an automatic heating rate adjustment system and an SMZ 745 Nikon stereomicroscope. The shrinking motion was recorded by a Nikon D90 digital camera mounted on the microscope. Acquisition and processing of images were performed using the image MHT software.

\section{Experimental, results and discussion Infrared spectroscopy}

The main FTIR-ATR absorption bands used to monitor the changes induced by the artificial, mixed-lightthermal ageing in the analysed parchment samples are listed in Table 1 which shows the three Amide bands which are most commonly used in infrared protein studies, namely Amide I, Amide II, and Amide III, and carbonyl/carboxyl band. As reported in the literature [39-43], the Amide I band found between 1600 and $1700 \mathrm{~cm}^{-1}$ is indicative of the stretching vibrations of the peptide carbonyl group $(\mathrm{C}=\mathrm{O})$ coupled weakly with $\mathrm{C}-\mathrm{N}$ stretching and $\mathrm{N}-\mathrm{H}$ bending. It is sensitive to local order, and its exact position is determined by the backbone conformation and the hydrogen-bonding pattern within the protein molecule. The Amide II band occurs at $1500-1600 \mathrm{~cm}^{-1}$ and is mainly derived from the $\mathrm{C}-\mathrm{N}$ stretch along with $\mathrm{N}-\mathrm{H}$ in-plane bending. Amide II is also sensitive to conformational changes. Finally, the Amide III band is found at $1200-1300 \mathrm{~cm}^{-1}$. The vibrations responsible for this band are a complex mix of $\mathrm{N}-\mathrm{H}$ bending and $\mathrm{C}-\mathrm{N}$ stretching along with deformation vibrations of $\mathrm{C}-\mathrm{H}$ and $\mathrm{N}-\mathrm{H}$. 
Table 1 List of the theoretical FTIR-ATR peak shift ranges of Amide I, Amide II, Amide III, and carbonyl/carboxyl compounds compared with the absorption maximums for the unaged parchment used in the experiments, and their relative vibrational modes

\begin{tabular}{lll}
\hline $\begin{array}{l}\text { Peak shift } \\
\text { ranges }\left(\mathbf{c m}^{-\mathbf{1}}\right) \\
\text { Literature }\end{array}$ & $\begin{array}{l}\text { Absorption peak frequency } \\
\left(\mathbf{\mathbf { c m } ^ { - 1 }}\right) \text { of unaged parchment }\end{array}$ & Vibrational mode \\
\hline $\mathbf{3 9 - 4 3}$ & & \\
\hline $1600-1700$ & 1635 & Amide I (AI) \\
$1500-1600$ & 1552 & Amide II (AII) \\
$1200-1300$ & 1239 & Amide III (AIII) \\
$1720-1750$ & 1740 & $(\mathrm{C}=\mathrm{O})$ \\
\hline
\end{tabular}

The Bruker Opus 7.0 software was utilized to compute the spectral average of the measurement points and, after normalisation and baseline correction, the area and the peak intensities of the relevant bands were calculated. The peak intensities of Amide I, Amide II, and Amide III bands were obtained by applying the "Opus $J$ integration mode" using the highest absolute peak intensity within pre-defined ranges of interest. The "Opus D integration mode" allows the calculation of the area below the spectrum within a defined range of wavenumbers and was applied for calculating the area of the Amide I band. The obtained data together with the cumulative shift of Amide I and Amide II bands $\left(\Delta v_{(\text {AI-AII })}\right)$ are summarized in Table 2 . Corresponding spectra are presented in Fig. 1.
In general, the variations of the shifts and intensities (expressed as peak height or peak area) are related to changes in the molecular structure of collagen, allowing us to identify and characterise the deterioration processes induced by mixed light-thermal ageing [44, 45]. One of the most pronounced effects of increased aging time observed in the FTIR-ATR spectra of the aged parchment was the cumulative displacement of the Amide I (AI) and Amide II (AII) bands expressed as the increase in their separation $\Delta v(\mathrm{AI}-\mathrm{AII})$. More precisely, for the samples PUV1 and PUV2, Amide II shifted progressively from $1552 \mathrm{~cm}^{-1}$ to 1530 and $1532 \mathrm{~cm}^{-1}$, respectively. It is shown in the literature that the absorbance of the Amide II peak decreased with the increase of UV radiation dose [21] and hydrogen atom transfer or structural scission of $-\mathrm{N}-\mathrm{H}$ was assigned to this event [19]. The peak at $1530 \mathrm{~cm}^{-1}$ represents a disordered structure of collagen, suggesting helix-random coil transformations [46]. With an increase of ageing time, Amide I shifted from $1635 \mathrm{~cm}^{-1}$ to 1648 and $1646 \mathrm{~cm}^{-1}$ for PUV1 and PUV 2, respectively. The prevalence of the component at $1632 \mathrm{~cm}^{-1}$ was attributed by Sellaro et al. [47] to mechanical stretching. The Amide I component at around $1630 \mathrm{~cm}^{-1}$ is the main component detected in spectra of fresh parchment [48]. Consequently, its shift towards $1646 \mathrm{~cm}^{-1}$ can be assigned to a redistribution of Amide I components as a result of conformational rearrangements of collagen exposed to artificial ageing. This progressive separation could therefore be related to a progressive conformational re-arrangement of the

Table 2 Results of FTIR-ATR analysis for the samples exposed to artificial ageing for a maximum of 748 h: PUV1 (exposed on grain side) and PUV2 (exposed on corium side)

\begin{tabular}{|c|c|c|c|c|c|c|c|}
\hline $\begin{array}{l}\text { Exposure time } \\
\text { (hours) }\end{array}$ & $\mathrm{vAl}\left(\mathrm{cm}^{-1}\right)$ & vAll $\left(\mathrm{cm}^{-1}\right)$ & $\Delta \mathbf{v}_{\text {(AI-AII) }}$ & $\mathrm{I}(\mathrm{Al})$ & $\mathrm{I}(\mathrm{AII})$ & I(AIII) & $\mathrm{a}(\mathrm{Al})$ \\
\hline \multicolumn{8}{|l|}{ PUV1 (grain side) } \\
\hline 0 & 1635 & 1552 & 83 & 0.27 & 0.206 & 0.093 & 144.97 \\
\hline 12 & 1635 & 1552 & 83 & 0.32 & 0.238 & 0.073 & 149.40 \\
\hline 83 & 1635 & 1546 & 89 & 0.09 & 0.066 & 0.057 & 157.96 \\
\hline 248 & 1640 & 1546 & 94 & 0.25 & 0.195 & 0.082 & 169.64 \\
\hline 392 & 1640 & 1541 & 99 & 0.14 & 0.103 & 0.057 & 175.83 \\
\hline 748 & 1646 & 1530 & 116 & 0.09 & 0.068 & 0.040 & 185.81 \\
\hline \multicolumn{8}{|c|}{ PUV2 (corium side) } \\
\hline 0 & 1635 & 1552 & 83 & 0.313 & 0.227 & 0.089 & 142.86 \\
\hline 12 & 1635 & 1549 & 86 & 0.330 & 0.235 & 0.079 & 148.87 \\
\hline 83 & 1640 & 1544 & 96 & 0.270 & 0.182 & 0.071 & 156.60 \\
\hline 248 & 1640 & 1540 & 100 & 0.244 & 0.173 & 0.09 & 168.17 \\
\hline 392 & 1645 & 1536 & 109 & 0.228 & 0.152 & 0.076 & 169.96 \\
\hline 748 & 1648 & 1532 & 116 & 0.160 & 0.110 & 0.063 & 180.41 \\
\hline
\end{tabular}

The wavenumber values of Amide I (vAI) and Amide II (vAll), the cumulative peak shift of Amide I and Amide II ( $\Delta \mathrm{v})$, the intensity of Amide I, II and III bands (I(AI), I(AII), $\mathrm{I}(\mathrm{AIII}))$, as well as the area of the Amide I peak $(\mathrm{a}(\mathrm{Al}))$ are listed for each mock-up at selected times 

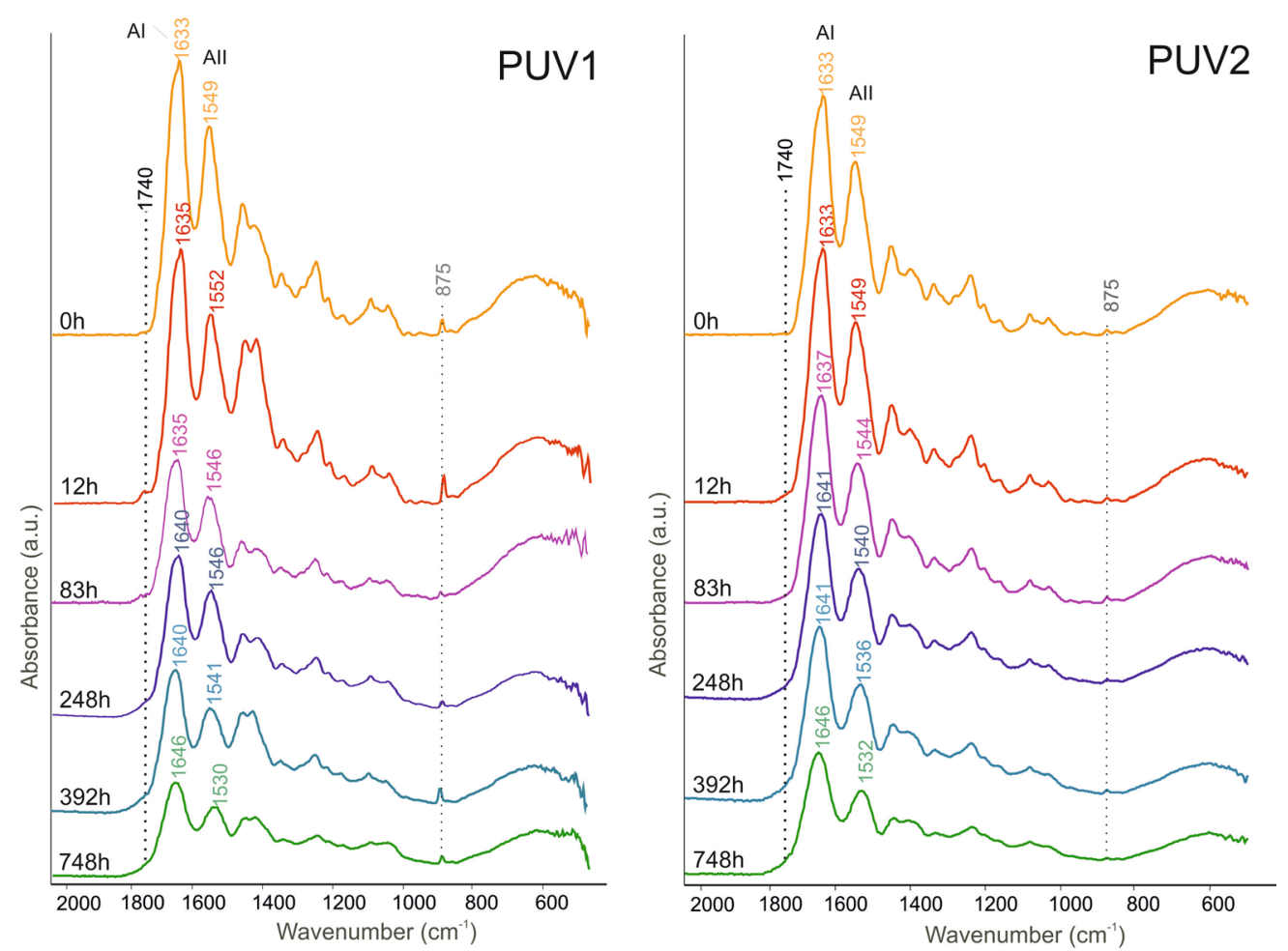

Fig. 1 FTIR-ATR spectra of PUV1 (grain side) and PUV2 (corium side) parchment samples exposed to artificial ageing for a maximum of $748 \mathrm{~h}$. Amide I and Amide II appear shifted and with progressively lower absorption intensity. Amide III shows progressively lower absorption intensity as well. The shoulder-type band at $1740 \mathrm{~cm}^{-1}$ occurs after $12 \mathrm{~h}$ of artificial ageing

native collagen molecules due to the weakening and then cleaving of covalent bonds near the residues in the single chains damaged by photo-oxidation. The progressive micro-unfolding process leading to collagen-destabilised intermediate states maintaining the triple helical structure was reported by Miles et al. [22], during the helixcoil degradation of collagen by UV light. Such states of collagen having lower thermal stability were identified as "intermediates" in the mechanism of collagen deterioration in both parchment (chemically unmodified collagen) and leather (chemically modified collagen) [15, 32, 49]. As deterioration continues, and enough covalent bonds are cleaved, the stability between neighbouring crosslinks drops in some locations below a lower limit, and the collagen molecules become highly unstable allowing for gelatinisation and irreversible denaturation (helix-coil conversion) [22, 32, 49, 50].

Another effect of ageing was the progressive decrease in the intensity of the Amide I, Amide II, and Amide III absorption bands. This common behaviour of Amide I, Amide II, and Amide III bands confirms the progressive cleavage of peptide bonds in the helical chains of the collagen molecules with ageing $[39,44]$. In addition, an absorption band in the range of $1720-1750 \mathrm{~cm}^{-1}\left(v_{\mathrm{C}=\mathrm{O}}\right)$ assigned to carbonyl or carboxyl compounds and considered as a marker of oxidation of the polypeptide chains, was detected as a shoulder just to the left of the Amide I band $[44,45]$. This band intensity can be related to the degree of the photo-oxidation process and was evaluated from the relative increase of the Amide I band area (a(AI)) reported in Table 2. We can thus infer that the photo-oxidation degree progressively increased with exposure time.

The presence of the band at $875 \mathrm{~cm}^{-1}$ is attributable to calcite derived from the liming step during the preparation of parchment. Its intensity is slightly higher on the grain side as expected.

It is also worth mentioning that similar spectral features were observed by the authors in old Italian and Romanian parchments (Fig. 2). For example, the shift of Amide II band towards $1523 \mathrm{~cm}^{-1}$ (Fig. 2, red line) was found when analysing the Biblia Magna from Novalesa Abbey (X-XI century) at the State Archives of Turin, Italy, while a cumulative shift of Amide I and Amide II bands (Fig. 2, blue line) was detected for some single sheet documents issued by the Stephen the Great Chancellery (XV century) owned by the Romanian Academy Library. Both spectra in Fig. 2 are also characterised by Amide III bands 


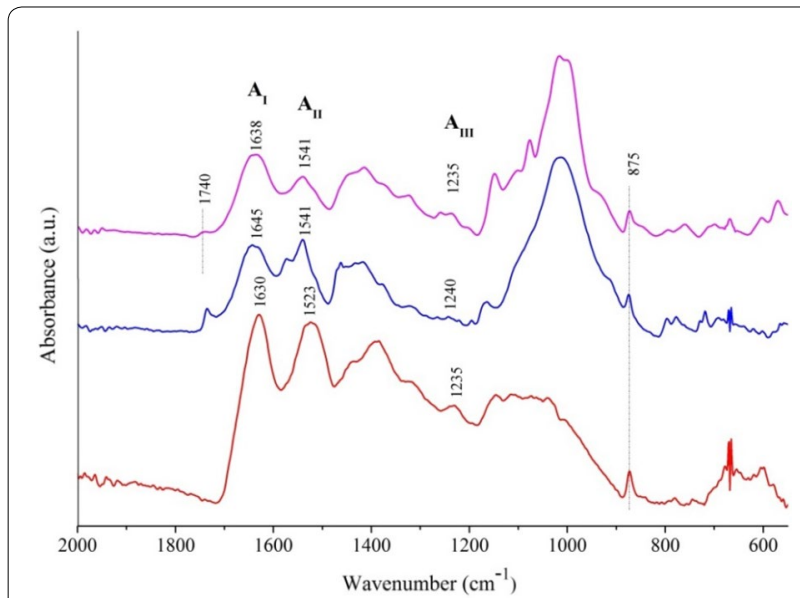

Fig. 2 FTIR-ATR spectra of some old parchments: red line-Biblia Magna, X-XI century, State Archives of Turin; blue line-Chancellery document, XV century, Romanian Academy Library; magenta lineparchment bookbinding, XVI century, Romanian Academy Library

with low absorption intensities. Additionally, almost half of the studied Chancellery documents showed a shoulder at $1740 \mathrm{~cm}^{-1}$ [51]. This shoulder (Fig. 2, magenta line) was also detected for some parchment book bindings (XVI century) from the Rare Books Collection of the Romanian Academy Library. All historical parchments presented the calcite absorption band as well.

To avoid possible effects due to inhomogeneity of the material and measure the strength of the linear relationship between ageing time and the spectral variables, statistical analysis of the results was performed. For this purpose, Pearson's correlation coefficient $(r)$ was calculated for both samples PUV1 and PUV2 using the correlation formula (1) and considering as variables the exposure time and Amide I peak area. This coefficient expresses the degree of concordance or discordance between the variables involved $(\mathrm{X}, \mathrm{Y})$, and it can range from -1.00 (perfect negative correlation) to +1.00 (perfect positive correlation) [52].

$$
r_{X Y}=\frac{\sum_{i=1}^{n}\left(X_{i}-\bar{X}\right)\left(Y_{i}-\bar{Y}\right)}{\sqrt{\sum_{i=1}^{n}\left(X_{i}-\bar{X}\right)^{2}} \sqrt{\sum_{i=1}^{n}\left(Y_{i}-\bar{Y}\right)^{2}}}
$$

Samples PUV1 and PUV2 both displayed a positive correlation $\left(\mathrm{r}_{\mathrm{PUV} 1}=+0.897\right.$ and $\left.\mathrm{r}_{\mathrm{PUV} 2}=+0.905\right)$ as well as a linear regression, with a high significance level (p-value $<0.01$ ). In order to estimate the accuracy of the statistical model (also defined as significance), the ANOVA (Analysis of Variance) was also performed confirming thus the linear covariance of the two variables. As a consequence, a linear relationship between the two variables can be inferred for both samples, i.e. by increasing the exposure time (independent variable), the Amide I area (dependent variable) increases (Fig. 3) [52, 53].

\section{Raman spectroscopy}

Raman spectroscopy is a powerful and a non-invasive method for the study of changes in the secondary structure of collagen that complements the FTIR technique well. In Raman spectroscopy, the frequency of the Amide I and Amide III bands usually reveal changes in the secondary structure. This region, along with lipids and proline and hydroxyproline regions, are the three main regions frequently involved in the conformational changes of collagen structure $[54,55]$. The bands in the Raman spectrum [54-57] used to monitor the artificial
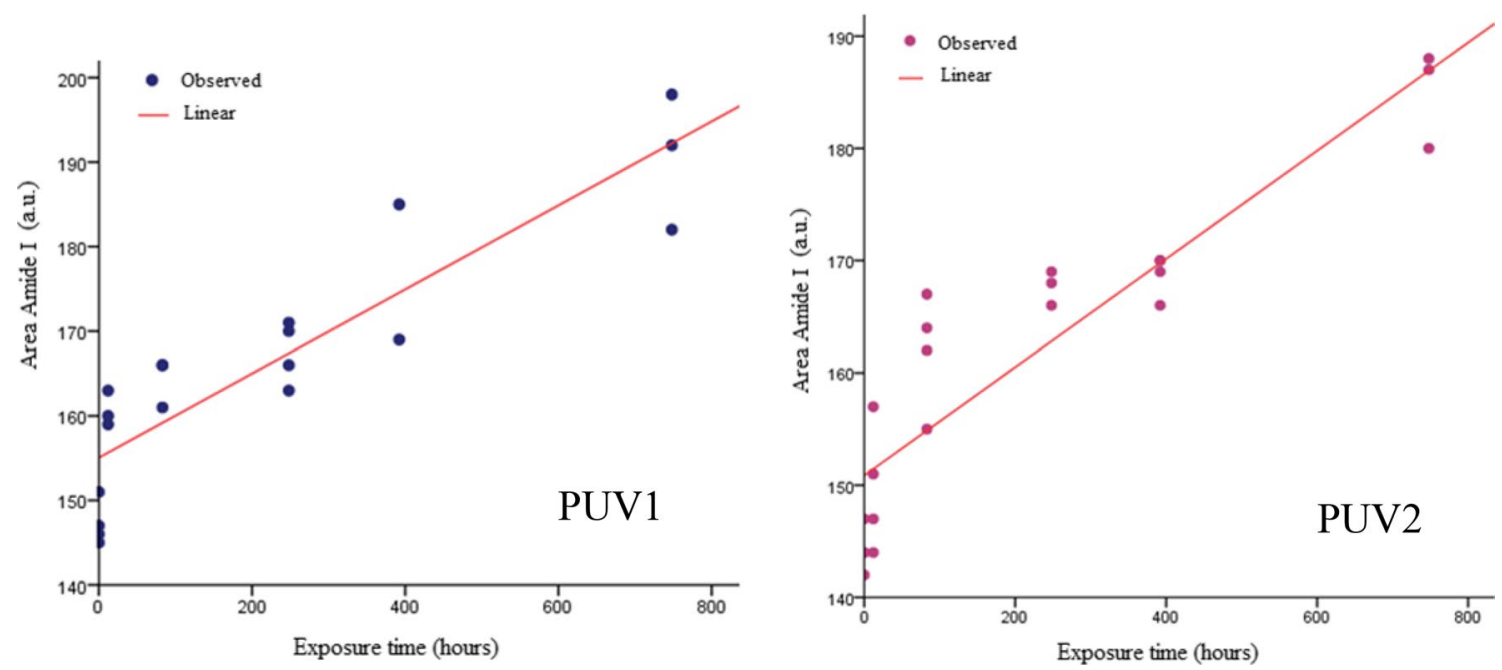

Fig. 3 Linear correlation between ageing time and Amide I peak area for PUV1 and PUV2 parchment samples 
Table 3 List of the theoretical Raman shifts of collagen in parchment compared with those obtained for the unaged parchment used in the accelerated ageing experiments, and their relative vibrational modes

\begin{tabular}{|c|c|c|}
\hline $\begin{array}{l}\text { Raman shifts } \\
\text { and ranges }\left(\mathrm{cm}^{-1}\right) \\
\text { Literature }[54-57]\end{array}$ & $\begin{array}{l}\text { Raman shift }\left(\mathrm{cm}^{-1}\right) \\
\text { of unaged parchment }\end{array}$ & Vibrational mode \\
\hline 3030 & 3030 & $v(\mathrm{CH})$ olefinic \\
\hline $1660-1670$ & 1660 & $v(C=O)$ Amide I \\
\hline 1550 & 1448 & $\delta\left(\mathrm{CH}_{2}\right)$ \\
\hline $1230-1260$ & 1233 & Amide III \\
\hline $800-1000$ & $800-1000$ & $\begin{array}{l}\mathrm{C}-\mathrm{C} \text { stretching of } \\
\text { Pro/Hypro ring } \\
\mathrm{C}-\mathrm{C} \text { stretching of } \\
\text { protein back- } \\
\text { bone }\end{array}$ \\
\hline
\end{tabular}

ageing-induced changes in the analysed parchment samples are listed in Table 3.

The main Raman spectral features of parchment exposed to artificial mixed light-thermal ageing are presented in Fig. 4. By comparing the spectra of PUV1 and PUV2, a slightly different ageing response was observed. In particular, for PUV1 (grain side), a spectral broadening occurred in the range from 1200 to $1700 \mathrm{~cm}^{-1}$ after $748 \mathrm{~h}$ of ageing. A decrease of the intensity of the $v(\mathrm{CH})$ olefinic band at $3300 \mathrm{~cm}^{-1}$ was recorded as well. In contrast, for PUV2 (corium side), neither the spectral broadening, nor the decrease of the $v(\mathrm{CH})$ olefinic band intensity were detected.

The Raman spectra of both samples PUV1 and PUV2 showed a shift of Amide I band from 1660 to $1648 \mathrm{~cm}^{-1}$ and $1652 \mathrm{~cm}^{-1}$, respectively, while a sharp decrease of peak intensity was observed as the exposure time increased. In addition, the small shoulder at $1630 \mathrm{~cm}^{-1}$ for PUV1 and at $1636 \mathrm{~cm}^{-1}$ for PUV2 disappeared after $392 \mathrm{~h}$ of exposure. The position of the Amide I band at $1660 \mathrm{~cm}^{-1}$ together with a shoulder at $1630 \mathrm{~cm}^{-1}$ indicates the presence of the $\alpha$-helix structure in the unaged material. The variations of these spectral features suggest a tendency to lose the $\alpha$-helix structure during the artificial ageing [54, 55]. This is in agreement with the FTIR-ATR results and confirms the formation of collagen-destabilised intermediate states at shorter ageing time and their further conversion to less ordered structures as ageing time increases. However, it should be mentioned that a visible broadening of the Raman spectra in the Amides I, II and III range for PUV1 was registered. As described in the literature and observed by Edwards et al. [57], this behaviour could be assigned once more to the loss of the $\alpha$-helix structure. This spectral aspect does not allow an objective evaluation of the Amide III band evolution during the ageing. Generally, it is known that when the Amide III band disappears, it is indicative that the hydrogen bonds that keep the $\alpha$-helix stable are breaking, leading to a more disordered collagen structure.

\section{Colorimetric measurements}

The colorimetric results are given as coordinates in the three-dimensional CIEL"a*b*(1994) color space, where $\mathrm{L}^{*}$ represents brightness on a scale from 0 (black) to 100 (white), $\mathrm{a}^{*}$ ranges from green $\left(-\mathrm{a}^{*}\right)$ to red $\left(+\mathrm{a}^{*}\right)$, and $b^{*}$ goes from blue $\left(-b^{*}\right)$ to yellow $\left(+b^{*}\right)$ [35]. For each sample, the average between the acquisition points, the changes in the single-color components $(\Delta \mathrm{a}$ and $\Delta \mathrm{b})$, in

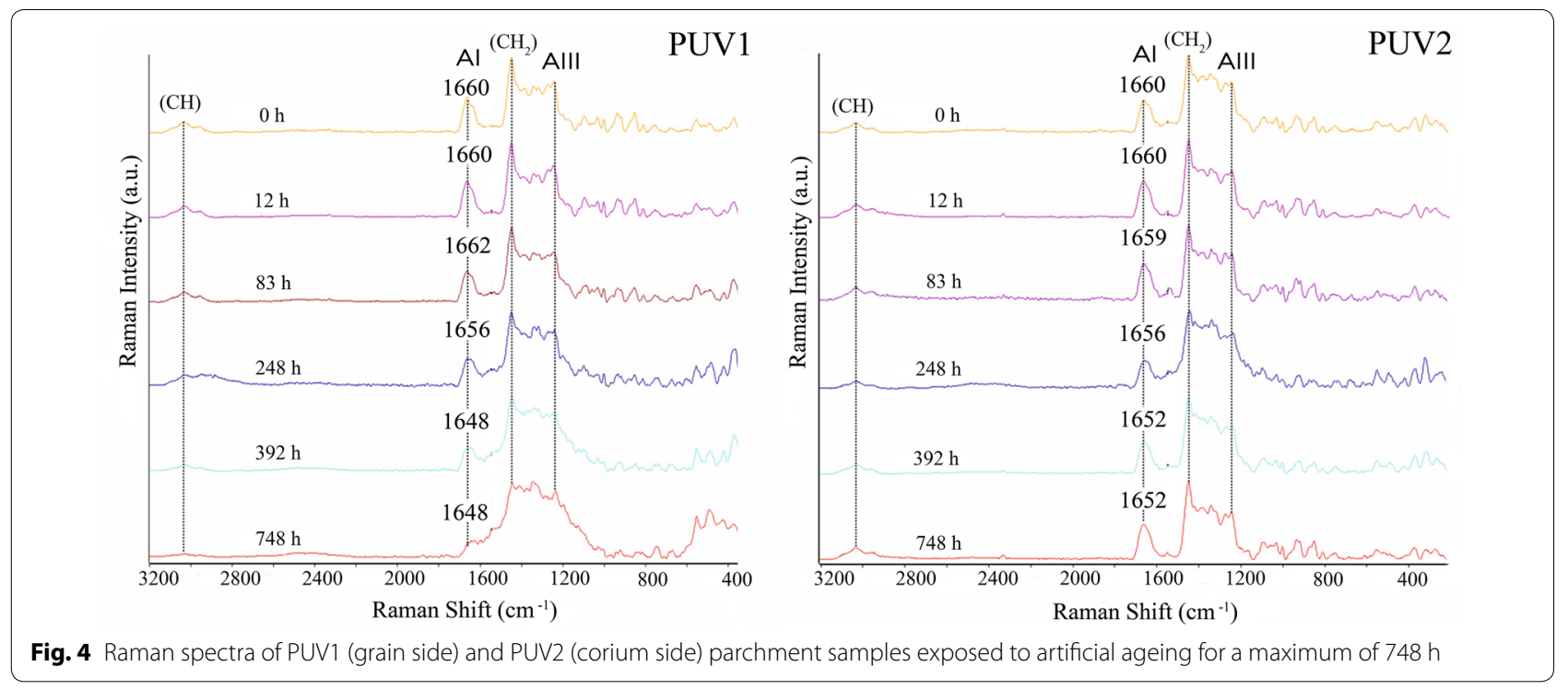


Table 4 Overall colour variation $(\Delta \mathrm{E})$, changes in colour coordinates $(\Delta a$ and $\Delta b)$ and brightness $(\Delta L)$ for PUV1 (grain side) and PUV2 (corium side) parchment samples exposed to artificial ageing for a maximum of $748 \mathrm{~h}$ with respect to their unaged condition

\begin{tabular}{llrrrr}
\hline Sample & Ageing time $(\mathbf{h})$ & \multicolumn{1}{l}{$\boldsymbol{L} \mathbf{L}$} & \multicolumn{1}{l}{$\boldsymbol{\Delta} \mathbf{a}$} & $\boldsymbol{\Delta} \mathbf{b}$ & $\boldsymbol{\Delta} \mathbf{E}$ \\
\hline PUV1 (grain side) & 12 & -0.28 & 0.48 & 2.48 & 2.54 \\
& 83 & 0.08 & 0.23 & 0.93 & 0.97 \\
& 248 & 0.06 & 0.18 & 0.75 & 0.78 \\
& 392 & -0.92 & 0.30 & 1.33 & 1.64 \\
& 748 & -1.84 & 0.66 & 2.80 & 3.41 \\
PUV2 (corium side) & 12 & -2.07 & -0.27 & 0.98 & 2.30 \\
& 83 & -1.47 & -0.26 & 0.20 & 1.51 \\
& 248 & -1.58 & -0.35 & 1.01 & 1.91 \\
& 392 & -1.88 & -0.29 & 1.22 & 2.26 \\
& 748 & -0.35 & -0.26 & 2.71 & 2.74 \\
\hline
\end{tabular}

brightness $(\Delta \mathrm{L})$, and the overall colour variation $(\Delta \mathrm{E})$ were calculated which is shown and summarized in Table 4.

The overall colour variation $\Delta \mathrm{E}$, is a metric for understanding how the human eye perceives colour difference. It can range between 0 and 100 . For values $\leq 1.0$, the colour difference is defined as not perceptible by human eyes, whereas for values closed to 100 colours became the exact opposite. CIEL*a"b* (1994) calculates $\Delta \mathrm{E} 128$ (polar opposites) [35].

The computed $\Delta \mathrm{E}$ values for samples PUV1 and PUV2 show a variation during the ageing process from 0.97 to 3.41 and from 2.30 to 2.74 , respectively. Such changes in the overall colour are also perceptible at a glance by human eyes. Concerning the brightness, a negligible variation $(\Delta \mathrm{L})$ was obtained for PUV1 (grain side) which showed a mild darkening only after $748 \mathrm{~h}$ of ageing. On the other hand, PUV2 (corium side) showed a decrease in brightness even after short exposure time. An overall slight decrease in brightness for parchment exposed to light (low-heat approach) ageing which was more pronounced on the grain side was also reported by Kern et al. [58]. The different values obtained for $\triangle \mathrm{E}$ and $\Delta \mathrm{L}$ between PUV1 and PUV2 could be related to the different responses to light-ageing of the protein constituting the grain and the corium sides of the parchment. As described by Herfeld [59], elastin and reticulin are additional components of the skin. Reticulins, in particular, show a higher concentration around the hair follicles (grain side). These proteins are less chemically stable than collagen, due to their chemical structure [60]. Therefore both photo-degradation, and the optical properties of the two sides of the

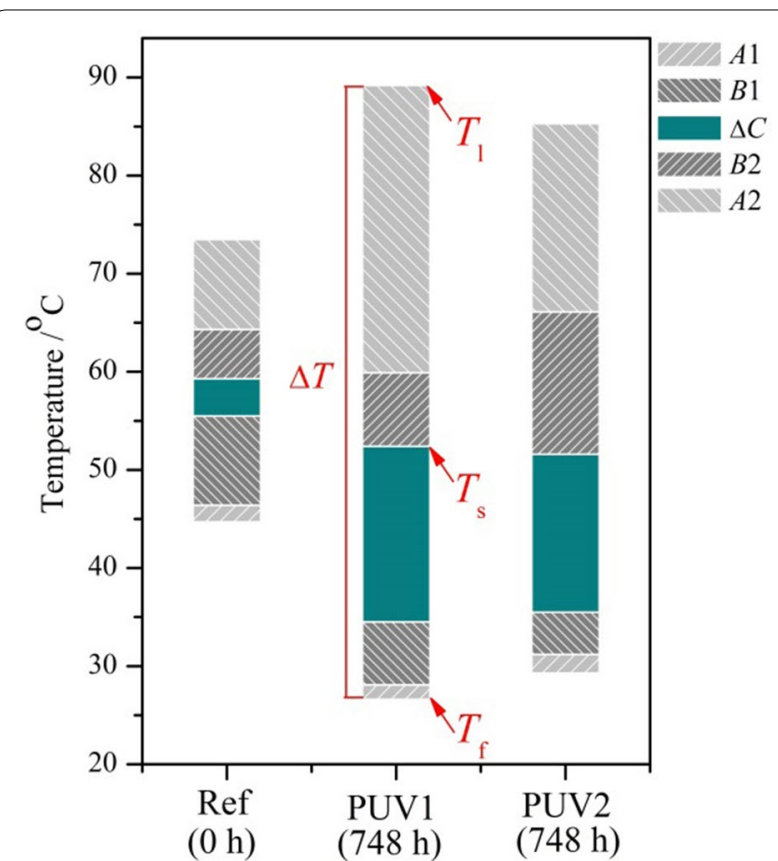

Fig. 5 Graphical presentation of the shrinkage intervals (A1, B1, $\triangle C$, $A 2, B 2)$ of PUV1 and PUV2 samples highlighting the temperature at which the shrinkage of the first fibre takes place $\left(T_{f}\right)$, the shrinkage temperature $\left(T_{s}\right)$, the temperature at which the last fibre shrinks $\left(T_{1}\right)$ and the total shrinkage interval $(\Delta T)$ for the parchment samples exposed to artificial ageing for $748 \mathrm{~h}$. The main shrinkage interval $\Delta C$ is highlighted in green

proteinaceous material are different, due to the differing concertation of these proteins in the skin matrix.

\section{Micro hot table method}

The degree of destabilisation of the organized collagen structure is well characterised by the shrinkage activity (MHT method) of collagen fibres in distinct temperature intervals. Generally, individual fibre shrinkage discretely occurs within A1, B1, B2, and A2 temperature ranges (Fig. 5), whereas the mass of fibres simultaneously shrinks within the so-called main temperature interval $\Delta C$. The starting temperature of this interval is the shrinkage temperature, $T_{\mathrm{s}}$. The total shrinkage interval $(\Delta T)$ is calculated as the difference between $T_{\mathrm{f}}$ (the temperature at which the very first shrinkage is observed) and $T_{1}$ (the temperature of the very last observed shrinkage). The shrinkage activity levels off through B2 and A2 intervals.

New parchments are characterised by $T_{\mathrm{s}}$ values in the (55-60) ${ }^{\circ} \mathrm{C}$ range and a total shrinkage interval of about $10{ }^{\circ} \mathrm{C}[36,37]$. The shrinkage intervals and temperatures of the samples aged for $748 \mathrm{~h}$ show a significant departure from the corresponding values measured for the unaged 
parchment (Fig. 4). For example, $T_{\mathrm{s}}$ and $T_{\mathrm{f}}$ dramatically decreased whereas $\Delta C$ and $\Delta T$ increased. $T_{\mathrm{s}}$ was about (35-36) ${ }^{\circ} \mathrm{C}$ while $\Delta T$ extended on a very large interval, i.e. $60{ }^{\circ} \mathrm{C}$. Furthermore, the $\Delta C$ interval increased from $4{ }^{\circ} \mathrm{C}$ to $16-18{ }^{\circ} \mathrm{C}$. This behaviour clearly indicates a strong thermal destabilisation and a high heterogeneity level, namely the presence of different collagen fractions with distinct thermal stabilities [7, 8, 12, 14, 15, 37], in agreement with the spectroscopic results. The very low values of $T_{\mathrm{f}}$ are due to the presence of highly unstable collagen populations, pregelatinized or even gelatinized [37]. On the other hand, the highly increased values of $T_{\mathrm{f}}$ could be assigned to a cross-linking induced by dehydration which draws the collagen molecules closer together $[15,49]$. A rather similar thermal behavior was observed in some old parchment manuscripts and book-bindings. For example, a restored single sheet document from the Royal Library in Copenhagen and a bookbinding from the States Archives of Florence showed $T_{\mathrm{s}}<40{ }^{\circ} \mathrm{C}$, $T_{1}>70{ }^{\circ} \mathrm{C}$ and large $\Delta C$ intervals. In these samples, the majority of the collagen fibres presented various morphological alterations (i.e. frayed, unwind, flat, cracked, fragmented, shrunk, gel-like) until the total loss of fibrillar structure [37]. Another example is represented by the manuscript of the Marco Polo's will (1324, Marciana National Library, Venice), characterised by large $\Delta C$ and $\Delta T$ intervals, whereas $T_{\mathrm{s}}$ lies around $43^{\circ} \mathrm{C}[61]$.

\section{Conclusions}

The FTIR-ATR and Raman techniques coupled with MHT method provided qualitative results that allowed us to characterise the ageing pattern of collagen in parchment exposed to light irradiation at $52{ }^{\circ} \mathrm{C}$ and $30 \% \mathrm{RH}$ for increasing time. The deterioration starts with the formation of collagen-destabilised intermediate states which still maintain a prevalent helical structure. As ageing continues for longer times, these helical structures tend to progressively convert to disorganised structures, i.e. pregelatinized collagen and gelatin. The most indicative FTIR-ATR spectral changes occurring with ageing time were: (i) the increase in the separation of amide I and amide II bands, attributed to conformational rearrangements of the native collagen molecules; (ii) the decrease of peak intensities of Amide I, Amide II, and Amide III, suggesting the progressive cleavage of peptide bonds in the helical chains of the collagen molecules; (iii) the occurrence and increase of a shoulder at $1740 \mathrm{~cm}^{-1}$ related to carbonyl/carboxyl compounds, as a result of photo-oxidation process. The most indicative Raman spectral characteristics were represented by the Amide I shift to lower wavenumbers together with the disappearance of the shoulder at $1630 \mathrm{~cm}^{-1}$, indicating a tendency to lose the $\alpha$-helix structure. The shrinking activity of collagen fibres in parchment aged for $748 \mathrm{~h}$ was characterised by very low values of both $T_{\mathrm{f}}$ and $T_{\mathrm{s}}$ (very low hydrothermal stability) and large $\Delta C$ (low fibre cohesivity) and $\Delta T$ intervals (very high structural heterogeneity). This behaviour reflects the presence of multiple collagen populations with distinct thermal stabilities and confirms the deterioration pattern revealed by FTIR-ATR and Raman techniques. In the FTIR-ATR results, no significant differences were observed between the corium and grain sides behaviour during artificially mixed light-thermal ageing, whereas differences in the Raman spectra were observed confirming a high degree of collagen-destabilised intermediate with loss of the $\alpha$-helix conformation, especially for the corium side. Correlation of the results obtained using vibrational spectroscopies and thermal microscopy provided a reliable protocol for the evaluation of the changes induced in parchment at molecular and fibrous levels.

\begin{abstract}
Abbreviations
MHT: micro hot table; FTIR-ATR: Fourier transform infrared spectroscopy in attenuated total reflection mode; $T_{s}$ : shrinkage temperature; $\Delta C$ : shrinkage interval; $\triangle \mathrm{T}$ : total shrinkage interval; UV: ultra violet; ARCH Lab: Advanced Research for Cultural Heritage Laboratory; INCDTP: National Research \& Development Institute for Textiles and Leather in Bucharest; T: temperature; RH: relative humidity; LED: light-emitting diodes; CCD: charge-coupled detector; LWD: long working distance; CIE (CIEL $\left.{ }^{*} a^{*} b^{*}\right)$ : International Commission on Illumination; Al: amide I; All: amide Il; All: amide III; $\triangle \mathrm{a}, \triangle \mathrm{b}$ : single-color components; $\Delta \mathrm{L}$ : brightness; $\Delta \mathrm{E}$ : overall color variation; $T$ f: temperature at which the very first shrinkage is observed; Tl: temperature of the very last observed shrinkage.
\end{abstract}

Acknowledgements

Austrian Science Fund (FWF), Grant Number P29892.

Authors' contributions

All authors read and approved the final manuscript.

Funding

Not applicable.

Availability of data and materials

Datasets as well as analytical information used for the current study are available from the corresponding author on reasonable request.

Ethics approval and consent to participate

Not applicable.

\section{Competing interests}

The authors declare that they have no competing interests.

\section{Author details}

${ }^{1}$ Institute of Natural Sciences and Technology in the Arts, Academy of Fine Arts Vienna, Schillerplatz 3, 1010 Vienna, Austria. ${ }^{2}$ Microchemistry and Microscopy Art Diagnostic Laboratory, University of Bologna, Via Guaccimanni 4, 48121 Ravenna, Italy. ${ }^{3}$ National Museum of Romanian History, CaleaVictoriei 12, 030026 Bucharest, Romania. ${ }^{4}$ Advanced Research for Cultural Heritage Laboratory (ARCH Lab), National Research \& Development Institute for Textiles and Leather, ICPI Research Division, Ion Minulescu 93, 031215 Bucharest, Romania. ${ }^{5}$ Department of Chemistry, Faculty of Sciences, University of Craiova, CaleaBucureşti 107 I, 200585 Craiova, Romania.

Received: 16 September 2019 Accepted: 20 January 2020

Published online: 12 February 2020 


\section{References}

1. Clemens R, Graham T. Introduction to manuscript studies. Ithaca: Cornell University; 2007.

2. Gualdoni F. Una Storia Del Libro. Dalla Pergamena aAmbroiseVollard. Skira; 2008. p. 11-2.

3. Chimica e Biologia Applicate Alla Conservazione Degli Archivi. Ministero per i Beni e Le Attività Culturali, Direzione Generale per Gli Archivi; 2002.

4. Nappo L. Pergamene Dipinte e Sistemi Di Montaggio. Campanotto: Una Nuova Metodica Di Restauro; 2008.

5. Kennedy CJ, Wess TJ. The structure of collagen within parchment-a review. Restaurator. 2003;24:2.

6. Kennedy CJ, Wess TJ. The use of X-ray scattering to analyse parchment structure and degradation. In: Bradley D, Creagh D, editors. Physical techniques in the study of art, archaeology and cultural heritage, vol. 1. 2006. p. 151-72.

7. Della Gatta G, Badea E, Ceccarelli R, Usacheva T, Mašić A. Assessment of damage in old parchment by DSC and SEM. J Therm Anal Calorim. 2005:82:637-49.

8. Badea E, Della Gatta G, Budrugeac P. Characterisation and evaluation of the environmental impact on historical parchment by DSC. J Therm Anal Calorim. 2011;104:495-506.

9. Fessas D, Signorelli M, Schiraldi A, Kennedy CJ, Wess TJ, Hassel B, Nielsen K. Thermal analysis on parchments I: DSC and TGA combined approach for heat damage assessment. Thermochim Acta. 2006;447:30-5.

10. Mühlen AK, Larsen R, Sommer DVP, Melin R. Degradation of collagen in parchment under the influence of heat-induced oxidation: preliminary study of changes at macroscopic, microscopic, and molecular levels. Stud Conserv. 2016;61(1):46-57.

11. Wess T, Orgel J. Changes in collagen structure: drying, dehydrothermal treatment and relation to long term deterioration. Thermochim Acta. 2000;365(1):119-28.

12. Budrugeac P, Badea E, Della Gatta G, Miu L, Comănescu A. DSC study of deterioration caused by environmental chemical pollutants to parchment, a collagen based material. Thermochim Acta. 2010;500:51-62.

13. Vest M, Jacobsen J, Larsen R. Accelerated ageing: effect of heat and relative humidity. In: Larsen $\mathrm{R}$, editor. Improved damage assessment of parchment-assessment, data collection and sharing of knowledge. Luxembourg: The European Commission; 2007. p. 67-8.

14. Badea E, Della Gatta G, Usacheva T. Effects of temperature and relative humidity on fibrillar collagen within parchment: a micro Differential Scanning Calorimetry (micro DSC) study. Polym Degrad Stab. 2012;97:346-53.

15. Badea E, Usacheva T, Della Gatta G. The use of differential scanning calorimetry to characterise collagen deterioration in parchment. Rossijskij Khimicheskij Zhurnal. 2015;59:28-41.

16. Manfredi M, Bearman G, France F, Shor P, Marengo E. Quantitative multispectral imaging for the detection of parchment ageing caused by light: a comparison with ATR-FTIR, GC-MS and TGA analyses. Int J Conserv Sci. 2016;6:13-4.

17. Dolgin B, Bulatov $\bigvee$, Schechter I. Non-destructive assessment of parchment deterioration by optical methods. Anal Bioanal Chem. 2007:388(5):1885-96.

18. Kaminśka A, Sionkowska A. The effect of UV radiation on the thermal parameters of collagen degradation. Polym Degrad Stab. 1996;51(1):15-8.

19. Kaminśka A, Sionkowska A. Effect of UV radiation on the infrared spectra of collagen Polym. Degrad Stab. 1996:51:19-26.

20. Sionkowska A. Modification of collagen films by ultraviolet irradiation. Polym Degrad Stab. 2000;68:147-51.

21. Sionkowska A. Effects of solar radiation on collagen and chitosan films. J Photochem Photobiol B Biol. 2006;82:9-15.

22. Miles CA, Sionkowska A, Hulin SL, Sims TJ, Avery NC, Bailey AJ. Identification of an intermediate state in the helix-coil degradation of collagen by ultraviolet light. J Biol Chem. 2000;275:33014-20.

23. Metreveli N, Namicheishvili L, Jariashvili K, Mrevlishvili G, Sionkowska A. Mechanisms of the influence of UV irradiation on collagen and collagenascorbic acid solutions. Int J Photoenergy. 2006;1:4.

24. Feller RL. Accelerated ageing: photochemical and thermal aspects. Marina del Rey: Getty Conservation Institute; 1994.

25. Davies MJ. Protein oxidation and peroxidation. Biochem J. 2016;473:805-25
26. Deasy CL, Michele SrSC. A study of the oxidative degradation of gelatin and collagen by aqueous hydrogen peroxide solution. J Am Leather Chem Assoc. 1965:60:665-74.

27. Vančíková O, Deyl Z. Disappearance of tyrosine residues in collagen with age. Suggestion of a possible reaction mechanism. Exp Gerontol. 1974;9:23-130.

28. Larsen $\mathrm{R}$. The possible link between the collagen sequence and structure and its oxidative deterioration pattern. In: Larsen R, editor. STEP leather project, research report no. 1, vol. 59. The Royal Danish Academy of Fine Arts; 1994. p. 74.

29. Anghelone M, Jembrih-Simbrih D, Schreiner M. Influence of phthalocyanine pigments on the photo-degradation of alkyd artists paints under different conditions of artificial solar radiation. Polym Degrad Stab. 2016:134:157-68.

30. Robinson J, Linder A, Gemmel A. Comparison of standard UV test methods for the ageing of cables. In: Proceedings of the international wire \& cable symposium (IWCS), vol. 60. 2011. p. 329-37.

31. Suri M, Huld TA, Dunlop ED, Cebecauer T. Potential of solar electricity generation in the European Union member states and candidate countries. Sol Energy. 2007;81:1295-305

32. Carşote C, Badea E, Miu L, Della Gatta G. Study of the effect of tannins and_animal species on the thermal stability of vegetable leather by differential scanning calorimetry. J Therm Anal Calorim. 2016;124(3):1255-66

33. Hansen EF, Lee $S N$, Sobel $H$. The effects of relative humidity on some physical properties of modern vellum. Implications for the optimum relative humidity for the display and storage of parchment. J Am Inst Conserv. 1992;31:325-42.

34. Kanagy JR. Influence of temperature on the adsorption of water vapor by collagen and leather. J Res Nat Stand. 1950;44:31-45.

35. Ohta N, Robertson A. Colorimetry: fundamentals and applications. New York: Wiley; 2006.

36. Larsen AR, Poulsen D, Vest M. The hydrothermal stability (shrinkage activity) of parchment measured by the microhot table method (MHT). In: Larsen R, editor. Microanalysis of parchment, vol. 93. London: Archetype Publications; 2002. p. 99.

37. Badea E, Sommer Dorte VP, Mühlen Axelsson K, Della Gatta G, Larsen R. Standardised methods for damage ranking in parchment: from microscopic evaluation to collagen denaturation assessment. e-Preserv Sci. 2012;9:97-109.

38. Badea E, Şendrea C, Carşote C, Adams A, Bluemich B, lovu H. Unilateral NMR and thermal microscopy studies of vegetable tanned leather exposed to dehydrothermal treatment and light irradiation. Microchem J. 2016;129:158-65.

39. Carsote C, Budrugeac P, Decheva R, Haralampiev NS, Miu L, Badea E. Characterization of a byzantine manuscript by infrared spectroscopy and thermal analysis. Rev Roum Chim. 2014;59(6-7):429-36.

40. Haris PI, Severcan F. FTIR spectroscopic characterization of protein structure in aqueous and non-aqueous media. J Mol Catal B Enzym. 1999;7:207-21.

41. Barth A, Zscherp C. What vibrations tell us about proteins. Q Rev Biophys. 2002;35:369-430

42. Glassford SE, Byrne B, Kazarian SG. Recent applications of ATR FTIR spectroscopy and imaging to proteins. Biochim Biophys Acta. 2013;1834:2849-58.

43. Coates J. Interpretation of infrared spectra, a practical approach. In: Meyers RA, McKelvy ML, editors. Encyclopedia of Analytical chemistry. 2006.

44. Badea E, Miu L, Budrugeac P, Giurginca M, Mašić A, Badea N, Della Gatta $\mathrm{G}$. Study of deterioration of historical parchments by various thermal analysis techniques complemented by SEM, FTIR, UV-Vis-NIR and unilateral NMR investigations. J Therm Anal Calorim. 2008;91(1):17-27.

45. Odlya M, Theodorakopoulos C, de Groot J, Bozec L, Horton M. Fourier transform infra-red spectroscopy (ATR/FTIR) and scanning probe microscopy of parchment. E-Preserv Sci. 2009;6:138-44.

46. Rabotyagova OS, Cebe P, Kaplan DL. Collagen structural hierarchy and susceptibility to degradation by ultraviolet radiation. Mater Sci Eng C Mater Biol Appl. 2008;28:1420-9.

47. Sellaro TL, Hildebrand D, Lu QJ, Vyavahare N, Scott M, Sacks MS Effects of collagen fiber orientation on the response of biologically derived soft tissue biomaterials to cyclic loading. J Biomed Mater Res. 2007:80A:194-205. 
48. Carsote C. Damage assessment of historical leathers and parchments, PhD thesis. University of Bucharest; 2017. p. 93-7.

49. Carsote C, Badea E. Micro differential scanning calorimetry and micro hot table method for quantifying deterioration of historical leather. Herit Sci. 2019;7:48.

50. Uversky VN. Natively unfolded proteins: a point where biology waits for physics. Protein Sci. 2002;11:739-56.

51. Badea E, Carsote C, Petroviciu I, Miu L, Brovarone AV, Della Gatta G. Archival and library parchments across West and East Europe: eveness and oddities. Restitutio Conserv Restor Bull. 2015;9:46-53.

52. "SPSS tutorials." 2018. https://www.spss-tutorials.com/pearson-correlatio n-coefficient/. Accessed 30 Oct 2018.

53. Fabbris L. Statistica multivariata: analisi esplorativa dei dati. Milano: McGraw-Hill Libri Italia; 1997.

54. Pelton JT, McLean LR. Spectroscopic methods for analysis of protein secondary structure. Anal Biochem. 2000;277:167-76.

55. Martinez MG, Bullock AJ, MacNeil S, Rehman IU. Characterization of structural changes in collagen with Raman spectroscopy. Appl Spectrosc Rev. 2019;54(6):509-42.

56. McColl IH, Blanch EW, Gill AC, Rhie AGO, Ritchie MA, Hecht L, Barron LD. A new perspective on sheet structures using vibrational Raman optical activity: from poly(_-lysine) to the prion protein. J Am Chem Soc. 2003;125(33):10019-26.
57. Edwards HGM, Perez FR. Application of Fourier transform Raman spectroscopy to the characterization of parchment and vellum. II-Effect of bio deterioration and chemical deterioration on spectral interpretation. J Raman Spectrosc. 2004;35(89):754-60.

58. Kern MS, Pataki-Hundt A, Wouters J, Kirby DP. Accelerated ageing of parchment: investigation of a photo catalysed, low-heat approach. Restaurator. 2018;39(1):33-69.

59. Herfeld H. Bibliothek des Leders, Band1-Die Tierische Haut. Frankfurt: Umschau Verlag; 1990.

60. Nielsen K. Visual damage assessment. IDAP, improved damage assessment of parchment, assessment, data collection and sharing of knowledge. Luxembourg: Larsen; 2007. p. 45-51.

61. Badea E, Carsote C.I segreti della pergamena del testamento di Marco Polo. In: Plebani T, editor. II Testamento di Marco Polo - II documento, la storia, il contest. Milan; 2019. p. 169-86.

\section{Publisher's Note}

Springer Nature remains neutral with regard to jurisdictional claims in published maps and institutional affiliations.

\section{Submit your manuscript to a SpringerOpen ${ }^{\circ}$ journal and benefit from:}

- Convenient online submission

- Rigorous peer review

- Open access: articles freely available online

- High visibility within the field

- Retaining the copyright to your article

Submit your next manuscript at $\gg$ springeropen.com 